\title{
Prevalence and Factors Associated With Rectal Vancomycin-Resistant Enterococci Colonization in Two Intensive Care Units in São Paulo, Brazil
}

Guilherme Henrique Campos Furtado, Sinaida Teixeira Martins, Ana Paula Coutinho, Sérgio Barsanti Wey and Eduardo Alexandrino Servolo Medeiros
Division of Infectious Diseases, Hospital Epidemiology Committee, Federal University of São Paulo, São

Paulo, SP, Brazil

\begin{abstract}
Vancomycin-resistant enterococci (VRE) are important pathogens causing nosocomial infections, and there is reason for concern about their resistance and great ability to spread in hospital environments, especially intensive-care units (ICU). To determine the prevalence of rectal colonization by VRE, and the risk factors associated with their presence, rectal surveillance swabs were taken from patients under treatment in two intensive-care units (one medical and another both medical and surgical) at São Paulo Hospital, over a two-year period. Thirty-three percent of the 147 patients evaluated had VRE. The only significant variable in the logistic regression was the length of stay in the ICU.

Key Words: Vancomycin-resistant enterococci, rectal colonization, intensive care unit.
\end{abstract}

Recently, vancomycin-resistant enterococci (VRE) have become important nosocomial pathogens because of their rapid spread [1], significant attributable mortality [2-5], limited options for therapy and risk of transfer of vancomycin resistance to virulent pathogens, such as Staphylococcus aureus, prompting the Centers for Disease Control (CDC) to publish guidelines in 1995 for the control of this pathogen in hospital environments; methods were suggested for the surveillance of colonization in the gastrointestinal tract, a major site of initial colonization. VRE was first isolated in Europe in 1988 [6]; subsequently there have been accounts of its presence in several other countries around the world. The percentage of nosocomial VRE infections in intensive care units (ICUs) reported to the NISS (Nosocomial Infections Surveillance System) of the CDC increased between 1993 and 1998 from 0.4\% to $13.4 \%$ [7], and the large, unrecognized population of patients who are colonized in ICUs are under risk

Received on 10 August 2004; revised 27 January 2004.

Address for correspondence: Dr. Guilherme H.C. Furtado. Rua Dr. Diogo de Faria, 1226/7, São Paulo, SP, Brazil..

E-mail:ghfurtado@uol.com.br.Fax:55-11-5571-8935

The Brazilian Journal of Infectious Diseases 2005;9(1):64-69 (C) 2005 by The Brazilian Journal of Infectious Diseases and Contexto Publishing. All rights reserved. of progression to infection. Colonization with VRE has been associated with a variety of factors, including length of hospital stay, underlying disease (particularly renal failure and neutropenia), liver transplantation, severity of illness, the presence of feeding tubes, proximity to colonized patients and antibiotic exposure, in particular treatment with certain antibiotics (e.g., cephalosporin, drugs with activity against anaerobic bacteria and vancomycin) [8,9]. In Brazil, vancomycinresistant enterococci (E. faecium) were initially described in 1996 in Curitiba, in a child with medullar aplasia [10]; consequently, surveillance cultures began to be adopted by various hospitals, in keeping with guidance from the CDC [11]. At our hospital, VRE (Enterococcus faecalis) was isolated for the first time in January 1998, from a surveillance rectal swab culture from a 23-year-old woman with Acute Lymphocytic Leukemia (ALL) [12]. Following this initial isolation, VRE began to be isolated continuously in surveillance rectal swabs at our general ICU, and it became, as in the rest of the world, a reason for concern for the hospital infection-control service staff, calling for the implementation of isolation and guidance measures in hospital communities. We began a surveillance study of these patients, endeavoring to define the prevalence of rectal colonization and associated risk factors in two 
ICUs (one medical and one medical-surgical), over a two-year period.

\section{Material and Methods}

São Paulo Hospital is a 660-bed tertiary school hospital, belonging to the Federal University of São Paulo, located in the city that is their namesake. Two ICUs were selected for the performance of weekly rectal surveillance swabs one was a medical and surgical ICU, with 16 beds and the other was a medical (pulmonary care) unit, with six beds. The study was done from January 2000 through December 2001.

All patients with over three days stay in the ICUs were submitted to rectal surveillance swabs and to weekly observation of rectal colonization. The swabs were sent to the Special Clinical Microbiology Laboratory and plated on a screening BHI plate containing $6 \mu \mathrm{g} / \mathrm{mL}$ vancomycin and incubated at $37^{\circ} \mathrm{C}$ for 24 hours. A Gram's stain was performed and Grampositive cocci were detected and subcultured on nonselective sheep blood agar. Identification was made by conventional methods proposed by Facklam and Collins [13]. Antimicrobial sensitivity was evaluated by disk diffusion and E-test (AB BIODISK, Solna, Sweden) methods [14]. An MIC for vancomycin $=32 \mu \mathrm{g} / \mathrm{mL}$ was considered resistant. Variables (listed in Table 13) were defined to evaluate the risk factors associated with VREcontracted in the ICUs. The data was analyzed using SPSS software (Version 10.0; SPSS Inc., Chicago, Il.). Continuous data was analyzed using the Student's $t$ test. Categorical data was assessed using Pearson's chisquare test. A P value of less than .05 was considered significant. The hospital's Institutional Review Board approved the study's protocol.

\section{Results}

A total of 265 swabs were obtained from 147 patients. Forty-eight patients had VRE-positive swabs, giving a positive rate of $32.6 \%$; 10 patients in this group were positive in clinical cultures $(20 \%)$, confirming hospital infection by CDC standards [15]. In the clinical ICUs, 23 swabs were gathered, 9 of which were positive, reflecting a prevalence of $39 \%$. In the medical-surgical ICU, 124 swabs were obtained; 39 were positive, with a prevalence of $31 \%$. A total of 32 variables were studied, of which 27 were categorical and 5 continuous (Table 1). The significant variables $(\mathrm{p}<0.05)$ were submitted to a multiple logistic regression, the results of which were as follows: prior hospitalization $(p=0.04)$, number of isolated bacteria $(\mathrm{p}=0.02)$, nosocomial infection $(\mathrm{p}=0.01)$, length of hospital stay $(p=0.002)$, length of ICU stay $(p<0.001)$ and period under antibiotic treatment $(\mathrm{p}=0.001)$. The only significant variable in the multiple logistic regression was the length of ICU stay, with an Odds Ratio $\left(\mathrm{CI}_{95}\right)$ of $4.5(1.7-7.3, \mathrm{p}=0.001)$.

\section{Discussion}

Vancomycin-resistantEnterococci are currently one of the pathogens of utmost prominence in hospitalinfection control, mostly due to their particular features: long-lasting colonization of the gastrointestinal tract, difficult decolonization and great ability for environmental colonization, facilitating their spread in hospital environments, notably in ICUs.

We evaluated the extent of colonization with VRE at two ICUs in a teaching hospital in São Paulo; the only risk factor significantly associated with VRE in patients under intensive-care conditions was the length of stay in the ICU. Edmond et al.[16] reported various risk factors for contracting VRE: extended hospitalization, ICU hospitalization, transplantation, hematological disease and use of antibiotics. Byers et al.[17], during an epidemic period, found $6 \%$ colonization in ICUs and wards, indicating as risk factors: proximity to an unisolated case of VRE, polytraumatism and use of metronidazol. We did not find association of VRE with the use of metronidazol or any other antimicrobial drug, though it was reported in other studies $[18,19]$.

Published reports support the hypothesis that after VCE are introduced, the rates of colonization and 
Table 1. Univariate analysis of Vancomycin-resistant Enterococci prevalence (percentages are given in parentheses)

\begin{tabular}{|c|c|c|c|c|}
\hline Variable & Class & Swab + (48) & Swab-(99) & $\mathbf{p}$ \\
\hline \multirow[t]{2}{*}{ Sex } & Male & $23(47.9)$ & $58(58.6)$ & 0.22 \\
\hline & Female & $25(52.1)$ & $41(41.4)$ & \\
\hline \multirow{2}{*}{ Outcome } & Death & $33(68.7)$ & $63(63.6)$ & 0.54 \\
\hline & Discharge & $15(31.2)$ & $36(36.4)$ & \\
\hline \multirow[t]{2}{*}{ Prior hospitalization } & No & $23(47.9)$ & $65(65.7)$ & 0.04 \\
\hline & Yes & $25(47.9)$ & $34(34.3)$ & \\
\hline \multirow[t]{2}{*}{ Diagnosis } & Medical & $18(37.5)$ & $44(44.4)$ & 0.42 \\
\hline & Surgical & $30(62.5)$ & $55(55.6)$ & \\
\hline \multirow[t]{2}{*}{ Parenteral nutrition } & No & $40(83.3)$ & $88(88.9)$ & 0.34 \\
\hline & Yes & $8(16.7)$ & $11(11.1)$ & \\
\hline \multirow[t]{2}{*}{ Arterial catheter } & No & $29(60.4)$ & $54(54.5)$ & 0.50 \\
\hline & Yes & $19(39.6)$ & $45(45.4)$ & \\
\hline \multirow[t]{2}{*}{ Central venous catheter } & No & $4(8.3)$ & $4(4.0)$ & 0.28 \\
\hline & Yes & $44(91.7)$ & $95(95.9)$ & \\
\hline \multirow[t]{2}{*}{ Nasogastric-enteral tube } & No & $3(6.2)$ & $3(3.0)$ & 0.35 \\
\hline & Yes & $45(93.7)$ & $96(96.9)$ & \\
\hline \multirow[t]{2}{*}{ Tracheal intubation } & No & $3(6.2)$ & $3(3.0)$ & 0.35 \\
\hline & Yes & $45(93.7)$ & $96(96.9)$ & \\
\hline \multirow{2}{*}{ Hemodialysis } & No & $45(83.3)$ & $92(92.9)$ & 0.07 \\
\hline & Yes & $8(16.7)$ & $7(7.07)$ & \\
\hline \multirow[t]{2}{*}{ Swan-Ganz catheter } & No & $34(70.8)$ & $72(72.7)$ & 0.81 \\
\hline & Yes & $14(29.2)$ & $27(27.3)$ & \\
\hline \multirow[t]{2}{*}{ Antiacid use } & No & $0 \quad(0.0)$ & $4(4.0)$ & 0.15 \\
\hline & Yes & $48(100.0)$ & $95(95.9)$ & \\
\hline \multirow[t]{2}{*}{ Blood Transfusion } & No & $7(14.6)$ & $21(21.2)$ & 0.33 \\
\hline & Yes & $41(85.4)$ & $78(78.8)$ & \\
\hline \multirow[t]{2}{*}{ Immunosupressive drug } & No & $45(93.9)$ & $92(92.9)$ & 0.85 \\
\hline & Yes & $3(6.2)$ & $7 \quad(7.1)$ & \\
\hline \multirow[t]{2}{*}{ Corticosteroid } & No & $16(33.3)$ & $48(48.5)$ & 0.08 \\
\hline & Yes & $32(66.7)$ & $51(51.5)$ & \\
\hline \multirow[t]{2}{*}{ Thoracic- abdominal surgery } & No & $34(70.8)$ & $66(66.7)$ & 0.61 \\
\hline & Yes & $14(29.2)$ & $33(33.3)$ & \\
\hline \multirow[t]{2}{*}{ Isolated bacteria } & Up to 1 & $24(50.0)$ & $69(69.7)$ & 0.02 \\
\hline & $>2$ & $24(50.0)$ & $30(30.3)$ & \\
\hline \multirow[t]{2}{*}{ Vancomycin } & No & $12(25.0)$ & $37(37.4)$ & 0.13 \\
\hline & Yes & $36(75.0)$ & $62(62.6)$ & \\
\hline \multirow[t]{2}{*}{$1 \mathrm{st} / 2^{\text {nd }}$ generation Cephalosporin } & No & $39(81.2)$ & $79(79.8)$ & 0.83 \\
\hline & Yes & $9(18.7)$ & $20(20.2)$ & \\
\hline \multirow[t]{2}{*}{$3 \mathrm{rd} / 4^{\text {th }}$ generation Cephalosporin } & No & $11(22.9)$ & $22(22.9)$ & 0.92 \\
\hline & Yes & $37(77.0)$ & $77(77.8)$ & \\
\hline \multirow[t]{2}{*}{ Carbapenens } & No & $23(47.9)$ & $60(60.6)$ & 0.14 \\
\hline & Yes & $25(52.1)$ & $39(39.4)$ & \\
\hline \multirow[t]{2}{*}{ Antianaerobic drug } & No & $26(54.2)$ & $58(58.6)$ & 0.61 \\
\hline & Yes & $22(45.8)$ & $41(41.4)$ & \\
\hline Nosocomial infection & No & $14(29.2)$ & $51(51.5)$ & 0.01 \\
\hline & Yes & $34(70.8)$ & $48(48.5)$ & \\
\hline Cancer & No & $36(75.0)$ & $73(73.7)$ & 0.87 \\
\hline & Yes & $12(25.0)$ & $26(26.3)$ & \\
\hline
\end{tabular}


Table 2. Univariate analysis of factors associated with Vancomycin-resistant Enterococci

\begin{tabular}{lccr}
\hline Variable & $\begin{array}{c}\text { Swab + (48) } \\
\text { Mean (range) }\end{array}$ & $\begin{array}{c}\text { Swab-(99) } \\
\text { Mean (range) }\end{array}$ & p \\
\hline Age (years) & $54.5(14-88)$ & $60.0(15-91)$ & 0.53 \\
Length of hospital stay (days) & $24.0(6-124)$ & $15.0(4-92)$ & 0.00 \\
Length of ICU stay (days) & $19.0(4-124)$ & $11.0(1-68)$ & $<0.05$ \\
Time under antibiotics (days) & $20.5(2-113)$ & $13.0(1-88)$ & $<0.05$ \\
Number of antibiotics & $4.0(1-8)$ & $4.0(1-7)$ & 0.06 \\
\hline
\end{tabular}

Table 3. Multivariate analysis of Vancomycin-resistant Enterococci cases

\begin{tabular}{lcc}
\hline Variable & Odds ratio $\left(\mathbf{C I}_{\mathbf{9 5}}\right)$ & $\mathbf{p}$ \\
\hline Length of ICU stay & $4.5(1.7-7.3)$ & 0.0012 \\
\hline $\mathrm{CI}=$ confidence interval. & &
\end{tabular}

infection increase and vancomycin-resistant enterococci become endemic unless effective control measures are introduced [20,21].

Ostrowski et al.[22] in an endemic period on the presence of VRE in a surgical ICU, found $12 \%$ colonization and the following risk factors: use of second and third generation cephalosporin, length of hospital stay, plus ICU hospitalization and solid-organ transplants. Advanced studies performed in ICUs, both in epidemic and endemic periods, have shown that cross contamination is the principal mechanism of VRE transmission [23,24]. This is one of the few reports of occurrence during an endemic period, but it indicated a lower colonization percentage than in our study, which was $32.6 \%$. Warren et al.[25], analyzing VRE epidemiology in a medical ICU, found as risk factors for colonization: hospitalization for over three days prior to ICU admission, chronic dialysis and having been admitted to the hospital once, twice or more over the previous 12 months.

VRE are important multidrug-resistant opportunistic pathogens in the hospital environment that are maintained by the selective pressure of widespread use of broad-spectrum antimicrobial drugs; they survive on the hands of health care workers and on inanimate objects [26]. VRE have been found in the stool of colonized patients, sometimes for extended periods. Effective control of VRE should address several factors, including judicious use of antibiotics, particularly vancomycin, cephalosporins and drugs with antianaerobic activity [11]. Patients who are infected or colonized with VRE should be isolated, preferably in private rooms. Some authors have suggested placing patients colonized or infected with VRE together [27]. Adherence to good handwashing procedures is critical unfortunately it is an area of infection control in which compliance is chronically deficient [9].

In 1995, the CDC recommendations to prevent the emergence and spread of vancomycin-resistant enterococci included the identification and isolation of patients colonized with vancomycin-resistant enterococci, hand washing by health care workers and cleaning of the environment [11]. After identification of the first case of VRE at our hospital in 1998 [12], the Hospital Epidemiology Committee began surveillance rectal cultures at two ICUs in order to identify and isolate patients who are colonized with VRE and consequently reduce the transmission of these strains to other patients.

We found a high prevalence of VRE colonization among the ICU patients $(32.6 \%)$; orientations concerning adherence to good handwashing procedures, isolation precautions and rational use of antibiotics were given to ICU personnel and repeated regularly after our study. Educational classes on the importance of VRE were given in group sessions, and 
guidelines were posted in each unit. We emphasize the growing importance of the vancomycin-resistant enterococci as nosocomial pathogens, causing, besides colonization, severe infections, such as bacteremias, urinary-tract and surgical-site infections [3,28]. The therapeutic arsenal presently available is quite scarce, with accounts of resistance to recently developed drugs (e.g. linezolide) [29]; there is also concern over the spread of resistance to Staphylococcus aureus through the vanA gene, recently described in the U.S. [30]. Continuous surveillance of this pathogen is thus required in hospital environments, especially in critical units, where high prevalence generally occurs, to avoid its progressive spread in hospitals, mainly those with unreported prior isolation. Surveillance of gastrointestinal-tract colonization is required, since the cases diagnosed in clinical cultures account for only $30 \%$ of colonized patients [31], and these colonized patients, as yet lacking clinical symptoms, are the main VRE disseminators in the hospital environment.

In summary, we found a high rate of VRE colonization at our ICUs, emphasizing the importance of length stay in the ICU as a risk factor for rectal colonization; these data made ICU personnel aware of the importance of infection control measures, including hand hygiene, isolation precautions, rational use of antimicrobial drugs, as well as rectal colonization surveillance, in order to decrease VRE prevalence.

\section{References}

1. Centers for Disease Control and Prevention. Nosocomial enterococci resistant to vancomycin- United States, 1989-1993. MMWR 1993;42:597-9.

2. Boyle J.F., Soumakis S.A., Rendo A., et al. Epidemiologic analysis and genotypic characterization of a nosocomial outbreak of vancomycin-resistant enterococci. J Clin Microbiol 1993;31:1280-5.

3. Edmond M.B., Ober J.F., Dawson J.D., et al. Vancomycinresistant enterococcal bacteremia: natural history and attributable mortality. Clin Infect Dis 1996;23:1234-9.

4. Stosor V., Peterson L.R., Postelnick M., Noskin G.A. Enterococcus faecium bacteremia: does vancomycin resistance make a difference? Arch Intern Med 1998; $158: 522-7$.
5. Linden P.K., Pasculle A.W., Manez R., et al. Differences in outcomes for patients with bacteremia due to vancomycin-resistant Enterococcus faecium or vancomycin-susceptible E. faecium. Clin Infect Dis 1996;22:663-70.

6. Uttley A.H.C., Collins C.H., Naidoo J., George R.C. Vancomycin-resistant Enterococcus. Lancet 1988; i: $57-8$.

7. Huycke M.M., Sahm D.F., Gilmore M.S. Multiple drugresistant Enterococcus: the nature of the problem and an agenda for the future. Emerg Infect Dis 1998,4:239-49.

8. Boyce J.M. Vancomycin-resistant enterococcus. Detection, epidemiology, and control measures. Infect Dis Clin North Am 1997; 11:367-84.

9. Gold H.S. Vancomycin-resistant enterococci: Mechanisms and Clinical Observations. Clin Infect Dis 2001; 33:210-9.

10. Costa L.M.D., Souza D.C., Martins L.T.F., et al. Vancomycin-resistant Enterococcus faecium: First case in Brazil. Braz J Infect Dis 1998;2(3):160-3.

11. Centers for Disease Control and Prevention (CDCHICPAC Hospital Infection Control Practices Advisory Committee). Recommendations for preventing the spread of vancomycin resistance. Infect Control Hosp Epidemiol 1995;16:105-13.

12. Cereda R.F., Sader H.S., Jones R.N., et al. Enterococcus faecalis resistant to Vancomycin and Teicoplanin (VanA Phenotype) isolated from a Bone Marrow Transplanted patient in Brazil. Braz J Infect Dis 2001;5:40-6.

13. Facklam R.R., Collins M.D. Identification of enterococcus species isolated from human infections by a conventional test scheme. J Clin Microbiol 1989;27:731-4.

14. Endtz H.P., Van Den Braak N., Belkum A., et al. Comparison of eight methods to detect Vancomycin resistance Enterococci. J Clin Microbiol 1998;36:592-4.

15. Garner J.S., Jarvis W.R., Emory T.G., et al. CDC definitions for nosocomial infections. Am J Infect Control 1988; $16: 128-40$.

16. Edmond M.B., Ober J.F., Wienbaum D.L., et al. Vancomycin-resistant Enterococcus faecium bacteremia: risk factors for infection. Clin Infect Dis 1995;20:1126-33.

17. Byers K.E., Anglim A.M., Anneski C.J., et al. The hospital epidemic of vancomycin-resistant Enterococcus: risk factors and control. Infect Control Hosp Epidemiol 2001;22:140-7.

18. Nourse C., Murphy H., Byrne C., et al. Control of the nosocomial outbreak of vancomycin-resistant Enterococcus faecium in the pediatric oncology unit: risk factors for colonization. Eur J Pediatr 1998; $157: 20-7$. 
19. Tornieporth N.G., Roberts R.B., John J., et al. Risk factors associated with vancomycin-resistant Enterococcus faecium infection or colonization in 145 matched-case patients and control patients. Clin Infect Dis 1996;23:767-72.

20. Bonilla H.F., Zervos M.A., Lyons M.J., et al. Colonization with vancomycin-resistant Enterococcus faecium: comparison of a long-term care unit with an acutecare hospital. Infect Control Hosp Epidemiol 1997; 18:333-9.

21. Morris J.G., Shay D.K., Hebden J.N., et al. Enterococci resistant to multiple antimicrobial agents,including vancomycin : establishment of endemicity in a university medical center. Ann Intern Med 1995; 123:250-9.

22. Ostrowski B.E., Venkataraman L., D'Agata, et al. Vancomycin-resistant Enterococcus in intensive-care units: high frequency of stool carriage during the nonoutbreak period. Arch Intern Med 1999;159:1467-72.

23. Boyce J.M., Opal S.M., Chow J.W., et al. Outbreak of multidrug-resistant Enterococcus faecium with transferable VanB-class vancomycin resistance. J Clin Microbiol 1994;32:1148-53.

24. Bonten M.J.M., Hayden M.K., Nathan C., et al. The epidemiology of patient colonization and environmental contamination with vancomycin-resistant Enterococcus: the challenge of infection control. Lancet 1996;348:1615-9.

25. Warren D.K., Kollef M.H., Seiler S.M., et al. The epidemiology of vancomycin-resistant Enterococcus colonization in the medical intensive-care unit. Infect Control Hosp Epidemiol 2003;24:257-63.

26. Noskin G.A., Stosor V., Cooper I., Peterson L.R. Recovery of vancomycin-resistant enterococci on fingertips and environmental surfaces. Infect Control Hosp Epidemiol 1995; $16: 577-81$.

27. Jochimsen E.M., Fish L., Manning K., et al. Control of vancomycin-resistant enterococci at a community hospital : efficacy of patient and staff cohorting. Infect Control Hosp Epidemiol 1999;20:106-9.

28. Wells C.L., Juni B.A., Cameron S.B., et al. Stool carriage, clinical isolation and mortality during an outbreak of vancomycin-resistant Enterococcus in hospitalized medical and/or surgical patients. Clin Infect Dis 1995;21:45-50.

29. Gonzalez R.D., Schreckenberger P.C., Graham M.B., et al. Infections due to vancomycin-resistant Enterococcus faecalis resistant to linezolide. Lancet 2001;357:1179.

30. Chang S., Sievert D.M., Hageman J., et al . Infection with vancomycin-resistant Staphylococcus aureus containing the van A resistance gene. $\mathrm{N}$ England $\mathrm{J}$ Med 2003;348:1342-7.
31. Zuckerman R.A., Steele L., Venezia R.A., Tobin E.H. Undetected vancomycin-resistant Enterococcus in surgical intensive-care-unit patients. Infect Control Hosp Epidemiol 1999;20:685-6. 